\title{
Importância e encadeamento dos setores de produção e abate e processamento da cadeia suinícola em Minas Gerais
}

\author{
Marielce de Cássia Ribeiro Tosta ${ }^{1}$ \\ Marília Fernandes Maciel Gomes ${ }^{2}$ \\ Viviani Silva Lirio ${ }^{2}$ \\ Suely de Fátima Ramos Silveira ${ }^{3}$
}

Resumo: O objetivo deste estudo foi determinar a importância e os encadeamentos dos setores de produção e abate e processamento da cadeia suinícola em Minas Gerais, nos anos de 1980 e 1995, por meio dos índices de Rasmussen-Hirschman, do campo de influência e do índice puro de ligação (GHS). De acordo com os resultados, ambos os setores analisados foram considerados setores-chave com base apenas no índice de Rasmussen-Hirschman e no campo de influência, ou seja, apresentaram maior relevância quando considerados os seus impactos na demanda final e os seus poderes de encadeamento na economia. Apesar de não terem sido considerados setores-chave pelo GHS, os setores de produção e abate e processamento apresentaram grande potencialidade de impactos para trás. Em face desses resultados e dado que esses setores continuaram aumentando a sua participação na economia de Minas Gerais nos anos subseqüentes a 1995, tem-se indicação de que estes devam ter prioridade na alocação de recursos e na estratégia de promoções industriais por meio de políticas estaduais.

\footnotetext{
${ }^{1}$ Doutoranda em Economia Aplicada do Departamento de Economia Rural, Universidade Federal de Viçosa, Viçosa-MG. E-mail: marielcetosta@yahoo.com.br

${ }^{2}$ Professoras doutoras do Departamento de Economia Rural, Universidade Federal de Viçosa, Viçosa-MG. E-mail: mfmgomes@ufv.br e vslirio@ufv.br

${ }^{3}$ Professora doutora do Departamento de Administração, Universidade Federal de Viçosa, Viçosa-MG. E-mail: sramos@ufv.br
} 
Palavras-chave: Cadeia suinícola, relações intersetoriais e desenvolvimento regional.

\section{Classificação JEL: R10}

Absract: The main objective of this study was to establish the importance and the enchainment of the production sector and butchery/making up sector of pork chain in Minas Gerais, in the years of 1980 and 1995, applying the Rasmussen-Hirschman index, the influence field index and GHS index. The results showed that both sectors were considered key sectors only by the Rasmussen-Hirschman index and the influence field index, i.e., they presented greater importance when observed its impacts on the final demand and its power of enchainment in the economy. Despite not being considered key sectors by the GHS index, they presented great potential of backward impacts. This result, and the fact that the participation of these sectors had been increasing in the Minas Gerais economy since 1995, suggests that those sectors the state policy makers need to give priority in resources allocation and in the strategy for the industrial development.

Key words: pork chain, inter sectors relations and regional development.

JEL Classification: $R 10$

\section{Introdução}

O complexo agroindustrial (CAI) pode ser entendido como o conjunto formado pela sucessão de atividades vinculadas à produção e à transformação de produtos agropecuários que envolvem a agropecuária em si e todo o conjunto produtivo, à montante e à jusante ${ }^{4}$. Quando a análise recai em produtos específicos, estabelecem-se as cadeias agroin-

\footnotetext{
${ }^{4}$ Entende-se por à montante o que antecede a produção agropecuária e engloba o conjunto de setores fornecedores de insumos e fatores de produção para as propriedades rurais; e por à jusante os setores que recebem a produção agropecuária para agregar valor, por meio do armazenamento, processamento ou distribuição para o consumidor final.
} 
dustriais. Os componentes dessas cadeias, por sua vez, constituem os setores responsáveis pelas diversas etapas do processo de produção, processamento e distribuição dos produtos agrícolas.

Com o objetivo de analisar a dimensão econômica, as mudanças estruturais e as tendências do CAI e das cadeias agroindustriais nacional e, ou regionais, têm sido desenvolvidos estudos que partem de uma visão sistêmica, nos quais são utilizadas matrizes de insumo-produto e considerados os fluxos e as transferências de insumos e de produtos entre os setores. Entre estes estudos destacam-se os de SANTANA (1994), MONTOYA e GUILHOTO (2000) e FURTUOSO e GUILHOTO (2003), que fizeram análises do CAI para a economia nacional, e os de CAVALCANTI (1991), FERNANDES (1997) e DIAWARA (2002), que analisaram CAI regionais.

Quanto às cadeias agroindustriais e aos setores específicos da matriz de insumo-produto, alguns estudos visaram analisar o setor agropecuário. BLISKA e GUILHOTO (2001) analisaram as cadeias de carnes nacionais (bovinos, suínos e aves), enquanto BLISKA et al. (2001), os setores da agropecuária e de abate e processamento de carnes, em diferentes regiões brasileiras.

Estudos desta natureza tornam-se relevantes porque, entre as cadeias que compõem o CAI, as agroindústrias de carnes têm papel importante e dinâmico no desenvolvimento econômico das regiões onde estão inseridas. Segundo COSTA et al. (2002), essas cadeias contribuem, expressivamente, para geração de renda, empregos e exportações e para geração de tributos federais, estaduais e municipais, principalmente por agregar valor à produção primária, além de aquecer a economia dos municípios, dado o efeito multiplicador das atividades ligadas indiretamente, bem como do segmento de prestação de serviços.

Em Minas Gerais, as três principais cadeias agroindustriais de carne são, em ordem de importância, a bovinocultura de corte, a avicultura e a suinocultura. Apesar de a cadeia agroindustrial de carne suína não ser a principal para a economia do estado, ressalta-se que os setores de produção e de abate e processamento apresentaram bom desempenho nos últimos anos, visto que o setor de produção detém o quarto maior rebanho suíno do país.

De acordo com PORDEUS e LOBATO (2002), o setor de produção obteve avanços notáveis durante a última década, dada uma expansão 
Importância e encadeamento dos setores de produção e abate e processamento da cadeia suinícola em Minas Gerais

de $67 \%$ no plantel de suínos, em comparação à avicultura (57\%) e à bovinocultura de corte (30\%). Segundo os Censos Agropecuários (IBGE, 1980 e 1995/96), a produção suína, que representava 9,94\% do valor total produção animal em 1980, aumentou para 13,07\%, em 1995. O seu crescimento também foi visível quanto a sua participação no valor bruto da produção na agropecuária mineira, já que, em 1985, essa atividade representava $2,29 \%$ deste valor e, em 1995 , passou para $6,03 \%$ (FUNDAÇÃO JOÃO PINHEIRO, 2002).

Além disso, cabe ressaltar também o crescimento do setor de abate e processamento da cadeia suinícola nos últimos anos. Em 1980, este setor, que correspondia a $3,73 \%$ da produção nacional, passou, em 2001 , para $7,18 \%$. No entanto, esse crescimento não ocorreu de forma linear, visto que toda década de 1980 foi marcada por baixa participação relativa deste setor em Minas Gerais. O grande salto do setor de abate e processamento ocorreu na década de 1990, principalmente até o ano de 1995, quando a produção deste no estado representou $11,23 \%$ da produção nacional (SUINOCULTURA INDUSTRIAL, 2003).

Os elevados crescimentos dos setores de produção e de abate e processamento da cadeia suinícola podem ser explicados pelo tipo de animais produzidos, pelo manejo sanitário e alimentar usado, pela produtividade alcançada nas granjas tecnificadas, pelo elevado consumo de carne suína in natura, pela maior procura por produtos semi-elaborados e/ou processados pela população e, ainda, pela inserção no mercado internacional, pelos ganhos tecnológicos e pelas alterações nas escalas de produção (GOMES, 2002).

Dessa forma, estes setores da cadeia suinícola ${ }^{5}$ do estado vêm apresentando condições necessárias para ampliarem o seu crescimento; no entanto, apesar da incessante busca de maior eficiência e competitividade por esses setores, ainda não se conhece a importância destes em agregar maior desenvolvimento ao estado, ou seja, os encadeamentos desses setores em relação aos demais setores da economia mineira.

Em face desse desconhecimento, este trabalho objetivou analisar os setores de produção e abate e processamento da cadeia suinícola

\footnotetext{
${ }^{5}$ Maiores informações sobre estes setores e sua relação com os demais da economia mineira ver TOSTA (2003).
} 
em Minas Gerais, nos anos de 1980 e 1995, com vistas a verificar seus encadeamentos na economia do estado. Especificamente, pretendeu-se: a) analisar a importância destes setores em Minas Gerais, especialmente com relação aos impactos gerados por alterações na demanda final e ao seu poder de encadeamento na economia mineira; e b) mensurar a importância destes setores em relação ao resto da economia e ao valor da produção do estado de Minas Gerais.

Dada a importância desses setores, é de esperar que aumentos em seus investimentos provoquem uma série de outros investimentos adicionais na economia, contribuindo, positivamente, para a estrutura econômica do estado e estimulando o crescimento econômico.

\section{Metodologia}

Em conseqüência das necessidades e dificuldades de priorizar algum setor da economia, para que este venha a ser estimulado, consolidou-se na literatura, de forma quase consensual, a noção de que reduzido número de setores tem a capacidade de desempenhar o papel de indutores no processo de transformação estrutural de um país ou região. Passaram, então, a ser genericamente denominados de setores-chave aqueles que, comprovadamente, exercem impactos para frente e para trás, acima da média, na economia.

Com efeito, a primeira e mais conhecida conceituação de setor-chave baseia-se nos índices de Rasmussen-Hirschman, de ligações para frente e para trás, e consiste em definir setores-chave como aqueles que apresentam ambos os índices superiores à unidade. Os índices de ligações para frente indicam que a produção de determinado setor é amplamente utilizada pelos demais e os índices de ligações para trás, que o setor é altamente dependente do restante da economia.

O problema é que essa definição requer que sejam atingidos, simultaneamente, os objetivos de demanda e de fornecimento de insumos por um mesmo setor. Dessa forma, alguns setores, como bens de capital, por exemplo, apesar de economicamente importantes nos efeitos para trás, como vendem sua produção para a demanda final, dificilmente despontariam como setores-chave, por apresentarem reduzidas interligações para frente (SANTANA e SOARES, 2000). 
Feita essa ressalva, pode-se definir o índice de ligação para frente ou índice de sensibilidade à dispersão do setor $i$ como a média dos elementos da linha $i$, da matriz inversa, dividida pela média de todos os elementos da matriz inversa, e o índice de ligação para trás ou índice de poder de dispersão do setor $j$, como a média dos elementos da coluna $j$, da matriz inversa, dividida pela média de todos os elementos da matriz inversa.

Índices de ligações para frente:

$$
U_{i}=\frac{1}{n} \sum_{j} b_{i j} / \frac{1}{\mathrm{n}^{2}} \sum_{i} \sum_{j} b_{i j} \quad(i, j=1,2, \cdots, n)
$$

Índices de ligações para trás:

$$
U_{j}=\frac{1}{n} \sum_{i} b_{i j} / \frac{1}{\mathrm{n}^{2}} \sum_{i} \sum_{j} b_{i j} \quad(i, j=1,2, \cdots, n)
$$

As dispersões dos índices de ligações para frente e para trás são determinadas por:

Índice de dispersão para frente:

$$
V_{i}=\sqrt{\frac{1}{\mathrm{n}-1} \sum_{j=1}^{n}\left(b_{i j}-\frac{1}{n} \sum_{j=1}^{n} B_{i j}\right)^{2}} / \frac{1}{\mathrm{n}} \sum_{\mathrm{i}=1}^{\mathrm{n}} \mathrm{B}_{\mathrm{ij}} \quad(\mathrm{i}, \mathrm{j}=1,2, \cdots, \mathrm{n})
$$

Índice de dispersão para trás:

$$
V_{j}=\sqrt{\frac{1}{\mathrm{n}-1} \sum_{i=1}^{n}\left(b_{i j}-\frac{1}{n} \sum_{i=1}^{n} B_{i j}\right)^{2}} / \frac{1}{\mathrm{n}} \sum_{\mathrm{j}=1}^{\mathrm{n}} \mathrm{B}_{\mathrm{ij}} \quad(\mathrm{i}, \mathrm{j}=1,2, \cdots, \mathrm{n})
$$

Os índices de dispersão mostram como os efeitos de ligação se espalham pelos demais setores. Quanto menor for o valor de $V_{i}$, maior será o número de setores nos quais o setor $i$ atuará, como fornecedor. Assim, se um setor tiver valor elevado para $U_{i}$ (superior a 1) e valor baixo para $V_{i}$, além de ter grande poder de encadeamento para frente, atingirá também muitos setores na matriz inversa. Por outro lado, quanto menor for o valor de $V_{j}$, maior será o número de setores relacionados com demanda intermediária induzida pelo setor $j$. Assim, se um setor tiver valor elevado para $U_{j}$ (superior a 1) e baixo valor para $V_{i}$, este setor, além de ter grande poder de encadeamento para trás, atingirá também muitos setores na matriz inversa. 
Em síntese, nesse contexto, um setor-chave é aquele em que $U_{i}$ e $U_{j}$ excedem a unidade e $V_{i}$ e $V_{j}$ são relativamente baixos.

A partir desse marco inicial, várias críticas seguiram aos índices de Rasmussen-Hirschman, e a maioria culminou na criação de novos tipos de índices de ligações que originaram, conseqüentemente, novas metodologias de identificação de setores-chave em uma economia, como o enfoque do campo de influência e os índices puros de ligação (GHS) utilizados neste trabalho.

O campo de influência permite verificar como se distribuem as mudanças dos coeficientes diretos no sistema econômico como um todo, possibilitando determinar que relações entre os setores são mais importantes no processo produtivo. Uma descrição mais detalhada do desenvolvimento do conceito de campo de influência pode ser encontrada em SONIS e HEWINGS (1989 e 1994).

Para determinar o campo de influência, necessita-se da matriz de coeficientes técnicos de produção, $A=\left|a_{i j}\right|$, e da definição de uma matriz de variações incrementais nos coeficientes diretos de insumo, $E=\left|\varepsilon_{i j}\right|$. As correspondentes matrizes inversas, de Leontief, são dadas por $B=(I-A)^{-1}=\left|b_{i j}\right|$ e por $B(\varepsilon)=[I-A-\varepsilon]^{-1}=\left|b_{i j}(\varepsilon)\right|$.

Segundo SONIS e HEWINGS (1989 e 1994), caso a variação tecnológica seja pequena e só ocorra num coeficiente direto, tem-se que o campo de influência dessa variação pode ser aproximado pela expressão

$$
F\left(\varepsilon_{i j}\right)=\frac{\left\lfloor B\left(\varepsilon_{i j}\right)-B\right\rfloor}{\varepsilon_{i j}},
$$

em que $F\left(\varepsilon_{i j}\right)$ é uma matriz (nxn) do campo de influência do coeficiente $\mathrm{a}_{\mathrm{ij}}$.

Para determinar os coeficientes diretos que têm maior campo de influência, associa-se cada matriz $F\left(\varepsilon_{i j}\right)$ a um valor, que é dado por $S_{i j}=\sum_{K=l}^{n} \sum_{l=1}^{n}\left[f_{k l}\left(\varepsilon_{i j}\right)\right]^{2}$.

Desse modo, os coeficientes diretos que possuem os maiores valores de $\mathrm{S}_{\mathrm{ij}}$ são os que têm maiores campos de influência na economia como um todo. 
Já o GHS permite identificar o grau dos impactos na demanda final em determinados setores, bem como dimensionar as interações destes com o valor da produção. A idéia básica é isolar determinado setor $j$ do restante da economia, com vistas a definir o efeito das ligações desse setor j na economia, ou seja, a diferença entre produção total da economia e produção na economia, caso o setor $j$ não comprasse insumos do resto da economia e não vendesse sua produção para o resto da economia. Essa situação equivale ao desaparecimento de todo o setor industrial (GUILHOTO et al., 1996).

Para isolar o setor $j$, considera-se um sistema de insumo-produto composto por dois setores e representado pelo bloco da matriz A, de insumos diretos: $A=\left[\begin{array}{cc}A_{j j} & \mathrm{~A}_{\mathrm{jr}} \\ A_{r j} & A_{r r}\end{array}\right]$,

em que $A_{\mathrm{jj}}$ e $A_{\mathrm{rr}}$ representam matrizes quadradas de insumos diretos, no primeiro e no segundo setor, respectivamente, e $A_{j r}$ e $A_{r j}$, matrizes retangulares dos insumos diretos adquiridos pelo segundo setor e vice-versa.

Da equação (8) pode-se chegar à seguinte expressão:

$$
B=(I-A)^{-1}=\left[\begin{array}{ll}
B_{j j} & \mathrm{~B}_{\mathrm{jr}} \\
B_{r j} & B_{r r}
\end{array}\right]=\left[\begin{array}{ll}
\Delta_{j j} & 0 \\
0 & \Delta_{r r}
\end{array}\right]\left[\begin{array}{ll}
\Delta_{j} & 0 \\
0 & \Delta_{r}
\end{array}\right]\left[\begin{array}{ll}
I & \mathrm{~A}_{\mathrm{jr}} \Delta_{r} \\
\mathrm{~A}_{\mathrm{rj}} \Delta_{\mathrm{j}} & I
\end{array}\right]
$$

em que os componentes de (9) são definidos por

$$
\begin{array}{ll}
\Delta_{j}=\left(I-A_{j j}\right)^{-1} & \Delta_{j j}=\left(I-\Delta_{j} A_{j r} \Delta_{r} A_{r j}\right)^{-1} \\
\Delta_{r}=\left(I-A_{r r}\right)^{-1} & \Delta_{r r}=\left(I-\Delta_{r} A_{r j} \Delta_{j} A_{j r}\right)^{-1}
\end{array}
$$

Pela decomposição de (9), é possível verificar como ocorre o processo de produção na economia. Na matriz $\left[\begin{array}{cc}I & \mathrm{~A}_{\mathrm{jr}} \Delta_{r} \\ \mathrm{~A}_{\mathrm{rj}} \Delta_{\mathrm{j}} & I\end{array}\right]$,

a primeira linha separa a demanda final pela sua origem, isto é, diferencia a demanda final interna, que vem de dentro do setor (I), da demanda final externa do setor $\left(A_{j r} \Delta_{r}\right)$. A mesma idéia aplica-se à segunda linha.

Partindo-se da formulação de Leontief, $X=(I-A)^{-1} Y$, e utilizandose as informações contidas em (9) e (11), derivam-se os índices puros: 


$$
P B L=\Delta_{r} A_{r j} \Delta_{j} Y_{j} \quad \text { e } \quad P F L=\Delta_{j} A_{j r} \Delta_{r} Y_{r} .
$$

O PBL indica o impacto puro do valor da produção total do setor $j$ no resto da economia $\left(\Delta_{j} Y_{j}\right)$, isto é, o impacto que é livre da demanda de insumos que o setor $j$ produz para o próprio setor $j$ e dos retornos do resto da economia para o setor $j$, e vice-versa. O PFL indica o impacto puro do valor da produção total do resto da economia $\left(\Delta_{j} Y_{r}\right)$ no setor $j$. Cabe salientar que tanto o PBL quanto o PFL são expressos em valores correntes e, portanto, podem ser somados para se obter o índice puro total das ligações (PTL).

Na realização deste trabalho utilizaram-se informações provenientes das matrizes de insumo-produto, calculadas por FERNANDES (1997) e SILVEIRA (2000), para Minas Gerais, nos anos de 1980 e 1995, respectivamente. No entanto, para atingir os objetivos propostos neste trabalho, essas matrizes foram abertas, com a finalidade de desagregar os setores "agropecuários" e "abate e processamento animal", e analisar, separadamente, os setores de produção e abate e processamento da cadeia suinícola. Para isso, desagregou-se o setor agropecuário em subsetores - agropecuária e suínos (produção) -, e o de abate e processamento animal - carne suína e outras carnes.

\section{Resultados e discussão}

Os índices de ligações para frente, de Rasmussen-Hirschman, nos anos de 1980 e 1995, são apresentados no Quadro 1. Observou-se, neste quadro, que os setores que apresentaram os maiores índices de ligações para frente, em ambos os anos analisados, foram: 1. Agropecuária, 4. Produtos não-metálicos e metalurgia básica, 17. Serviços, 7. Produtos químicos e 9. Fabricação de produtos alimentícios e bebidas. Os setores 2. Suínos e 10. Carne suína apresentaram índices de ligações para frente, respectivamente, na $9^{a}$ e na $17^{a}$ posição, em 1980 , e na $7^{\text {a }}$ e na $17^{a}$ posição, em 1995. 
Importância e encadeamento dos setores de produção e abate e processamento da cadeia suinícola em Minas Gerais

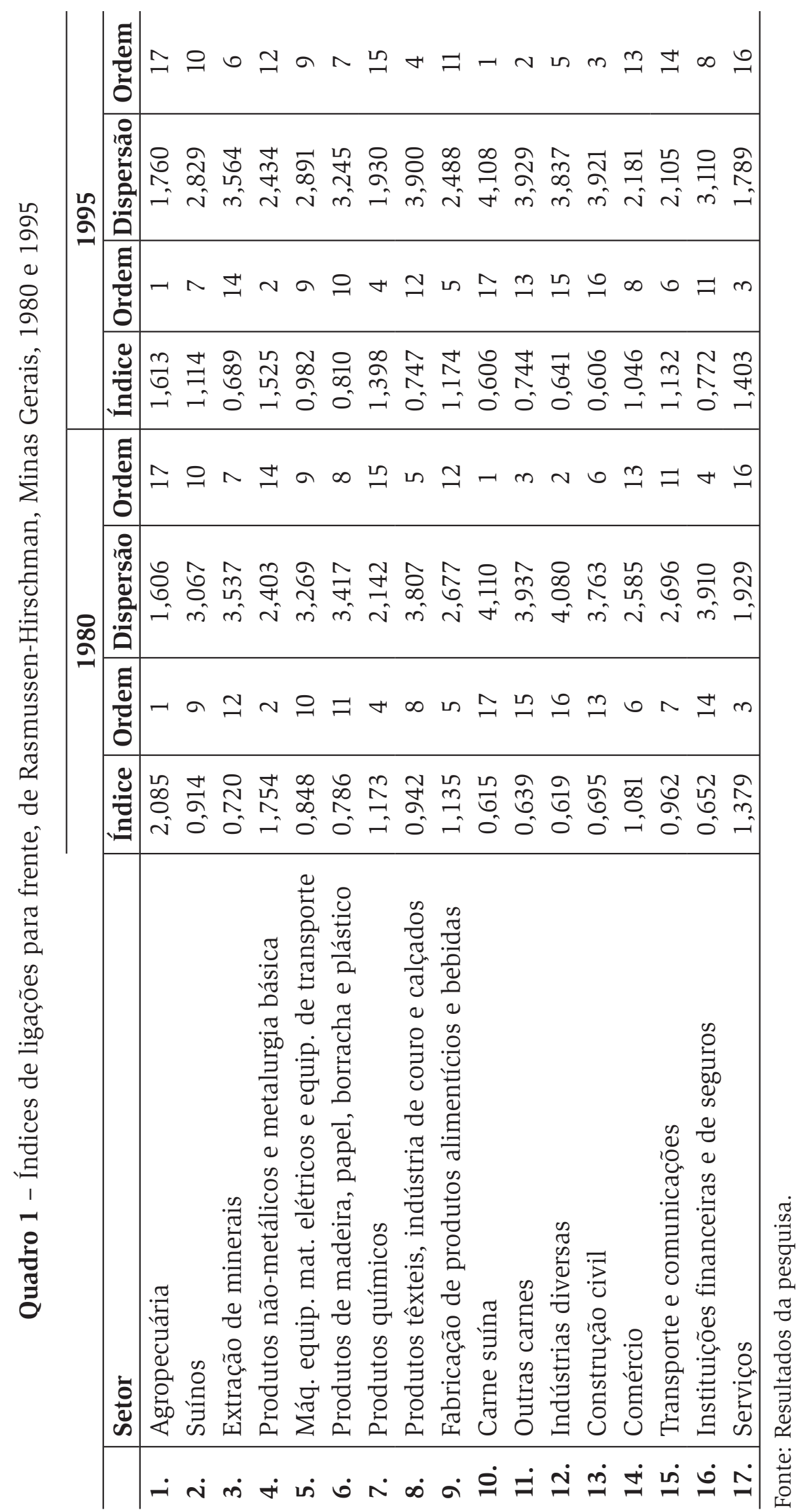


Tais resultados indicam que o setor 2. Suínos tornou-se mais dinâmico na ótica da oferta, ao passar da $9^{a}$ posição no escalonamento do índice, em 1980, para a $7^{\text {a }}$ posição, em 1995, admitindo, ainda, valor maior que a unidade, o que demonstra a grande importância do setor para o fornecimento de insumos para outros setores da economia.

O setor 10. Carne suína, por sua vez, apresentou os mais baixos valores para o índice de ligação para frente, nos dois anos analisados, o que indica que, dentre todos os setores da economia mineira, este se encontra mais relacionado com a demanda final.

Os resultados dos índices de dispersão (Quadro 1) demonstraram que o setor 2 . Suínos apresentou o $10^{\circ}$ maior valor de dispersão, tanto em 1980 quanto em 1995, o que indica que ele é demandado por maior número de setores e que uma variação na produção desse setor teria impacto mais bem distribuído nos demais. O setor 10. Carne suína apresentou o $1^{\circ}$ valor, o que demonstra que a demanda desse setor, nos dois períodos analisados, está presente em poucos setores da economia, razão pela qual estímulo decorrente de um impacto em sua produção deveria concentrar-se em poucos setores da economia.

Os resultados deste estudo diferiram, em parte, dos obtidos por BLISKA e GUILHOTO (2001), que desenvolveram um estudo semelhante do ano de 1995, para o Brasil, e encontraram baixo valor do índice de ligação para frente nos setores suínos e de carne suína. O resultado encontrado por estes autores para o setor suíno não correspondeu ao detectado neste estudo, no qual foi encontrado valor maior que a unidade para o índice de ligação para frente, destacando-se a importância do setor no estado de Minas Gerais, em detrimento dos demais estados do país. Quanto ao setor 10, o resultado deste estudo foi similar ao obtido por aqueles autores, o que indica a relação deste com a demanda final.

O Quadro 2 apresenta os resultados dos índices de ligações para trás. Os setores que apresentaram os mais altos índices de ligação para trás, em ambos os anos analisados, foram: 2. Suínos, 4. Produtos nãometálicos e metalurgia básica, 10. Carne suína, 11. Outras carnes e 9. Fabricação de produtos alimentícios e bebidas. Ressalta-se que os setores 2 e 10 apresentaram altos índices de ligações para trás, ocupando a $1^{\text {a }} \mathrm{e}$ a $3^{\mathrm{a}}$ posição, respectivamente, em 1980 , e a $2^{\mathrm{a}}$ e a $1^{\mathrm{a}}$ posição, respecti- 
Importância e encadeamento dos setores de produção e abate e processamento da cadeia suinícola em Minas Gerais

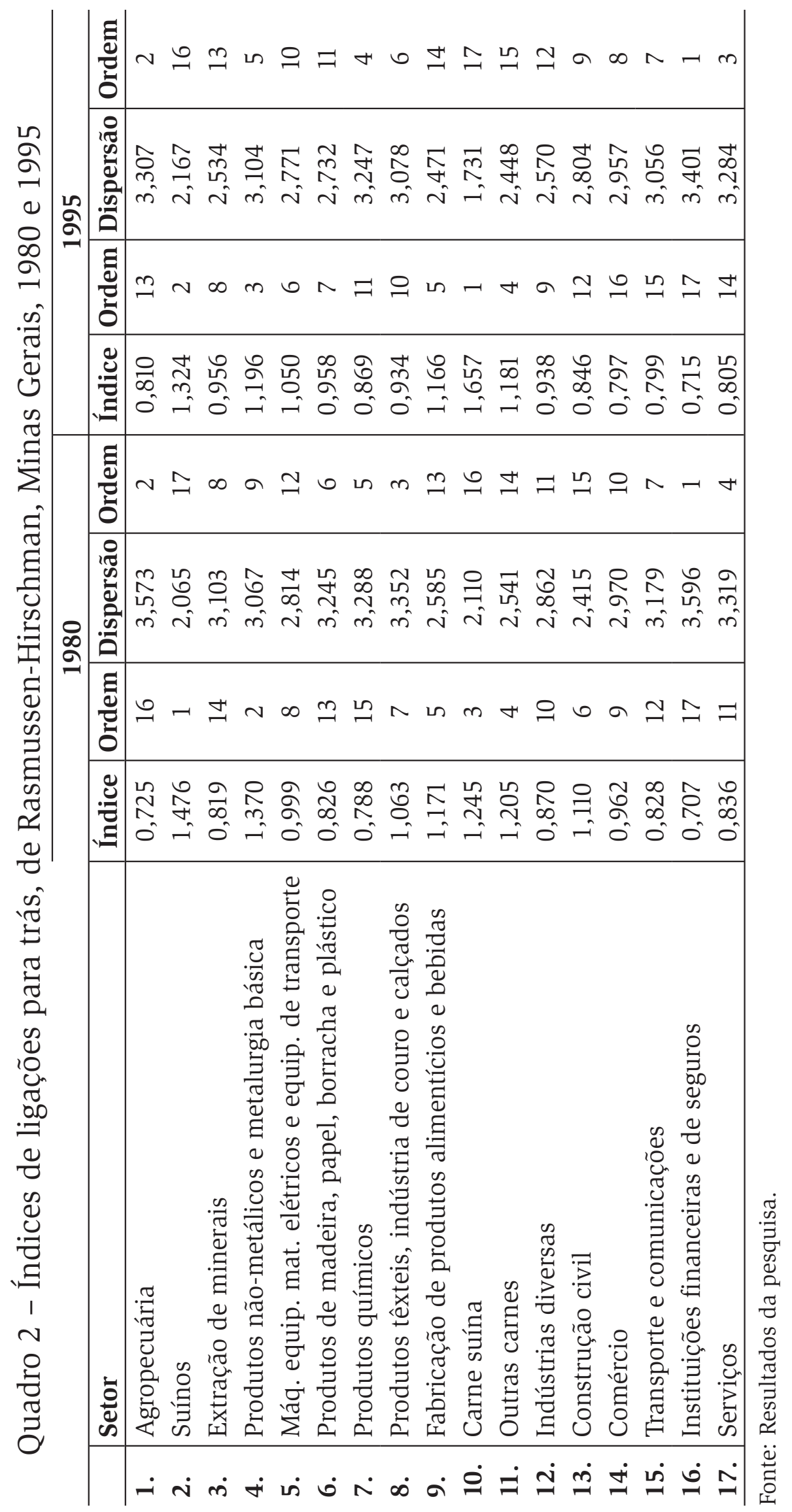


vamente, em 1995. Este resultado intensifica a importância destes para a economia do Estado de Minas Gerais.

Com relação à dispersão dos índices de ligações para trás (Quadro 2), observa-se que tanto o setor 2 quanto o 10 apresentaram baixos valores, em comparação aos outros, respectivamente o $17^{\circ}$ e $14^{\circ}$ valor, em 1980 , e o $16^{\circ}$ e $15^{\circ}$, em 1995. Esses resultados indicam que o impacto de uma variação na produção desses setores deveria estimular maior número de setores da economia, dado que quanto menor o valor do índice, maior o número de setores relacionados com demanda intermediária induzida por ele.

Quanto aos resultados encontrados neste estudo para o índice de ligação para trás, estes diferiram, em parte, dos obtidos por BLISKA e GUILHOTO (2001), que encontraram índice maior que a unidade para o setor suíno. No entanto, o valor do índice de ligação para trás do setor de carne suína não correspondeu ao deste trabalho, o qual apresentou valor maior que a unidade. A justificativa para essa diferença nos resultados deste setor, pode estar relacionada com dois fatores. $\mathrm{O}$ primeiro reside na diferença de objeto de estudo, isto é, ao se analisar o Brasil, consideram-se todos os estados da Federação, cuja maioria não possui eficiência nesta área, logo, há tendência de que este valor seja menor. O segundo está relacionado com a própria característica do setor 10 em Minas Gerais, que é responsável por todo o abate da produção realizada no estado, razão de sua relevância na economia.

Considerando-se setores-chave da economia os que apresentaram tanto índices de ligação para frente como de ligação para trás maiores que a unidade, verificou-se que apenas os setores 4 e 9 foram considerados setores-chave na economia mineira, em ambos os anos analisados. No entanto, no caso de adotar um conceito menos limitado desse critério e considerar setores-chave aqueles que apresentaram ou índice de ligação para frente ou para trás maior que a unidade, poder-se-iam considerar os setores 2 e 10 como setores-chave para a economia mineira.

Os resultados obtidos neste estudo são similares aos de FERNANDES (1997), SILVEIRA (2000) e DUARTE FILHO e CHIARI (2002), para o Estado de Minas Gerais, com o diferencial de que, nestes estudos, os setores da cadeia suinícola estavam agregados.

Para complementar a análise do índice de Rasmussen-Hirschman, foi calculado o Campo de Influência para Minas Gerais, nos anos de 1980 e 1995. Para isso, foram escolhidos 95 coeficientes setoriais, para 
cada um dos anos analisados, que tinham maior campo de influência na estrutura econômica do estado, plotados nas Figuras 1 e 2, cujos eixos discriminam os setores considerados neste trabalho.

De acordo com o campo de influência, os principais elos de ligações da economia do Estado de Minas Gerais, em 1980 (Figura 1), foram dominados pelos setores 1. Agropecuária, 2. Suínos, 4. Produtos nãometálicos e metalurgia básica, 8. Produtos têxteis, indústria de couro e calçados, 9. Fabricação de produtos alimentícios e bebidas, 14. Comércio e 17. Serviços.

Figura 1 - Campo de influência, Minas Gerais, 1980.

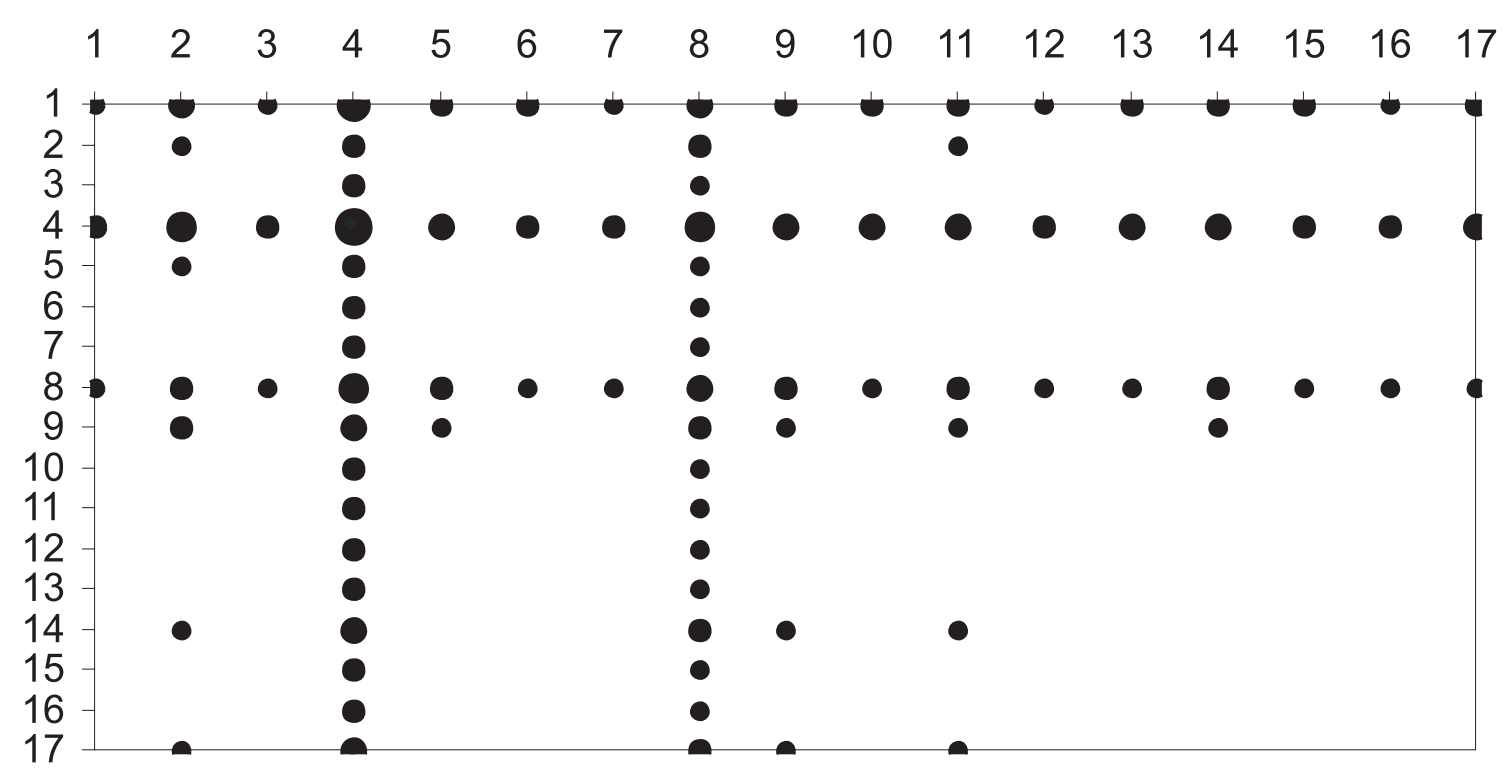

Fonte: Resultados da pesquisa.

O setor 2 apresentou baixa capacidade de influenciar os demais, dada uma variação em seus coeficientes de produção. Porém, percebeu-se a importância deste para os demais, como demandante de insumos, pois apresentou oito coeficientes de compra. O setor 10 apresentou capacidade ainda mais baixa de influenciar a economia do estado em 1980, visto que ressaltou apenas três coeficientes de compra, ou seja, teve pequena capacidade de influência para trás.

No ano de 1995 (Figura 2), observou-se aumento no número de setores que poderiam gerar impactos no sistema econômico. Com exceção do setor 14, os demais apresentados em 1980 repetiram os efeitos 
em 1995, englobando os setores 5. Máquinas, equipamentos, materiais elétricos e equipamentos de transporte, 7 . Produtos químicos, 10. Carne suína e 11. Outras carnes.

Figura 2 - Campo de influência, Minas Gerais, 1995.

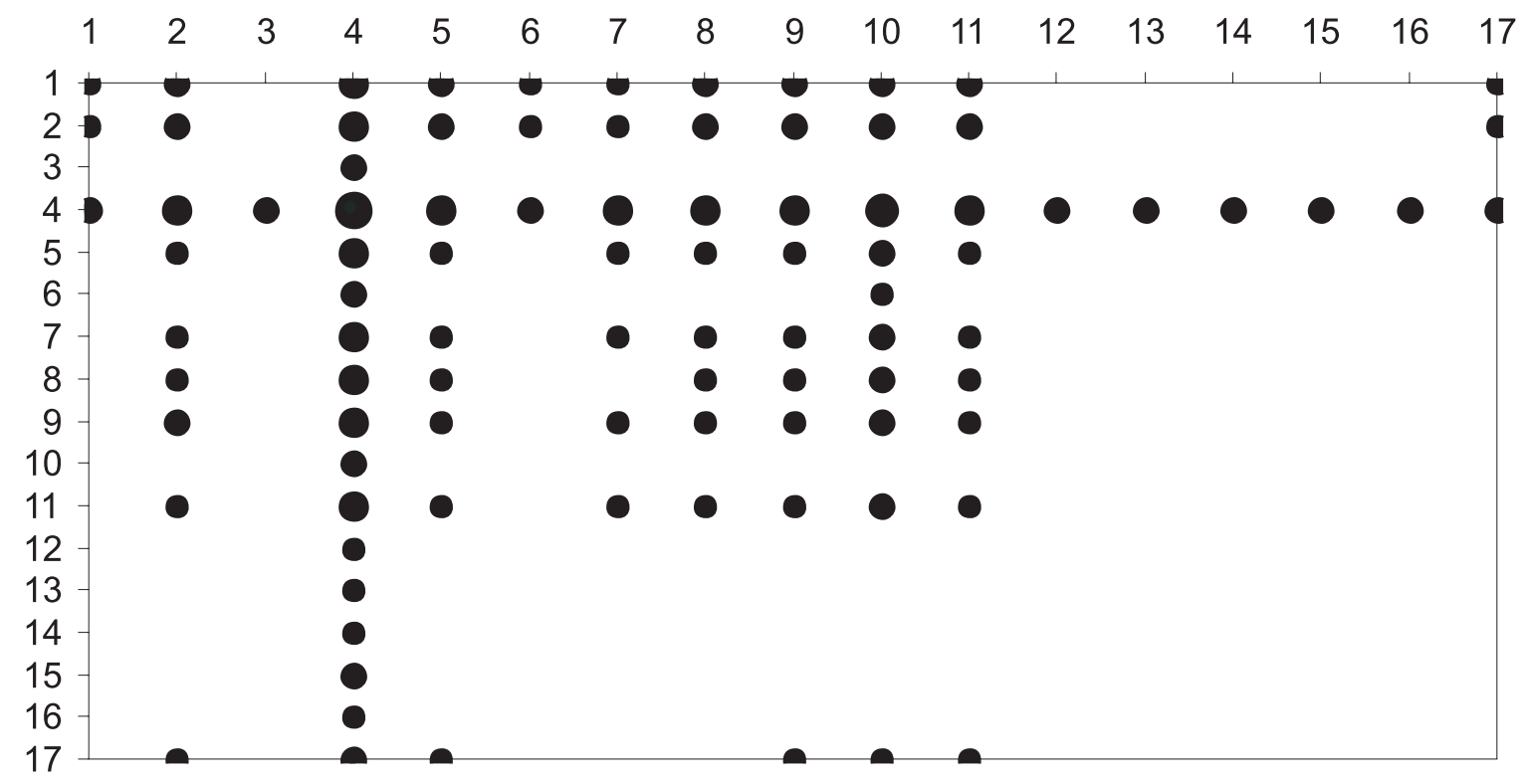

Fonte: Resultados da pesquisa.

O setor 2 apresentou, em 1995, maior capacidade de influenciar os demais, do que a apresentada em 1980, passando de oito coeficientes a nove, quanto à compra, e de quatro, em 1980, para 11, quanto à venda, em 1995. Tais resultados indicam, mais uma vez, o grande desenvolvimento desse setor.

Quanto ao setor 10, o resultado deste reafirmou a sua grande capacidade de influenciar para trás, pelo índice de Rasmussen-Hirschman, dado que apresentou 10 coeficientes de compra e apenas um de venda, em 1995. Assim, tornou-se evidente que uma variação no coeficiente de produção desse setor influenciaria, expressivamente, os setores que forneciam insumos para sua produção, que é voltada para a demanda final.

Para mensurar a importância dos setores 2 e 10, em relação ao resto da economia e ao valor da produção, foi utilizada a abordagem GHS, cujos resultados são medidos em valores monetários e estão apresentados em cruzeiros correntes de 1980 e em reais correntes de 1995. De 
acordo com valores obtidos pelo índice puro de ligação total (PTL), consideram-se como setores-chave os que apresentaram valores acima da média estadual.

Nos Quadros 3 e 4, os campos em negrito indicam os setores-chave, nos anos de 1980 e 1995, da economia de Minas Gerais, a saber: 1. Agropecuária, 4. Produtos não-metálicos e metalurgia básica, 7. Produtos químicos, 9. Fabricação de produtos alimentícios e bebidas, 14. Comércio e 17. Serviços. É possível observar, entretanto, pequena alteração na estrutura da economia nos anos de 1980 e 1995, e que neste último ano houve maior número de setores-chave.

De acordo com o GHS, os setores-chave reforçaram as indicações dos índices de Rasmussen-Hirschman. Porém, ressalta-se que o PTL apresentou maior número de setores dinâmicos, uma vez que este considera não apenas a estrutura interna da economia, como Rasmussen-Hirschman, mas também o valor de produção em cada setor.

A composição do PTL para o setor 2, em 1980, indicou que 52,20\% de sua estrutura provinha do PFL, contrário ao valor do índice de RasmussenHirschman no mesmo ano, que apresentou índice de ligação para trás maior que o de ligação para frente. Em 1995, no entanto, houve unicidade entre os valores encontrados pelos índices, ao indicar impacto maior para trás. 
Quadro 3 - Índices puros de ligações para trás, para frente e total, Minas Gerais, 1980, em milhões de cruzeiros

\begin{tabular}{c|cccccccc}
\hline \multirow{2}{*}{ Setor } & Trás & Ordem & $\begin{array}{c}\text { Frente } \\
\text { (PBL) }\end{array}$ & & Ordem & Total & Ordem & \multicolumn{2}{c}{$(\%)$} \\
\cline { 6 - 9 } & & & & (PTL) & & PBL & PFL \\
\hline 1 & 10508 & 12 & 112064 & 1 & $\mathbf{1 2 2 5 7 2}$ & 4 & 08,57 & 91,43 \\
2 & 3912 & 16 & 4272 & 15 & 8183 & 15 & 47,80 & 52,20 \\
3 & 18672 & 9 & 13345 & 10 & 32017 & 11 & 58,32 & 41,68 \\
4 & 76895 & 4 & 107581 & 2 & $\mathbf{1 8 4 4 7 5}$ & 1 & 41,68 & 58,32 \\
5 & 37067 & 7 & 26551 & 7 & 63618 & 9 & 58,26 & 41,74 \\
6 & 5831 & 13 & 19749 & 8 & 25580 & 12 & 22,79 & 77,21 \\
7 & 4502 & 14 & 65480 & 4 & $\mathbf{6 9 9 8 2}$ & 7 & 06,43 & 93,57 \\
8 & 12970 & 10 & 7491 & 12 & 20461 & 13 & 63,39 & 36,61 \\
9 & 81325 & 3 & 11444 & 11 & $\mathbf{9 2 7 6 9}$ & 6 & 87,66 & 12,34 \\
10 & 4141 & 15 & 166 & 17 & 4307 & 16 & 96,14 & 03,86 \\
11 & 37751 & 6 & 4976 & 14 & 42727 & 10 & 88,35 & 11,65 \\
12 & 1263 & 17 & 1173 & 16 & 2436 & 17 & 51,83 & 48,17 \\
13 & 122084 & 1 & 18146 & 9 & $\mathbf{1 4 0 2 3 0}$ & 3 & 87,06 & 12,94 \\
14 & 48362 & 5 & 53969 & 5 & $\mathbf{1 0 2 3 3 1}$ & 5 & 47,26 & 52,74 \\
15 & 22507 & 8 & 44972 & 6 & 67479 & 8 & 33,35 & 66,65 \\
16 & 11091 & 11 & 6977 & 13 & 18068 & 14 & 61,39 & 38,61 \\
17 & 89428 & 2 & 89468 & 3 & $\mathbf{1 7 8 8 9 7}$ & 2 & 49,99 & 50,01 \\
\hline Média & $\mathbf{3 4 6 0 6}$ & & $\mathbf{3 4 5 7 8}$ & & $\mathbf{6 9 1 8 4}$ & & & \\
\hline
\end{tabular}

Fonte: Resultados da pesquisa. 
Quadro 4 - Índices puros de ligações para trás, para frente e total, Minas Gerais, 1995, em mil reais

\begin{tabular}{c|cccccccc}
\hline \multirow{2}{*}{ Setor } & Trás & Ordem & $\begin{array}{c}\text { Frente } \\
\text { (PBL) }\end{array}$ & & Ordem & Total & Ordem & \multicolumn{2}{c}{$(\%)$} \\
\cline { 6 - 9 } & (PFL) & & (PTL) & & PBL & PFL \\
\hline 1 & 1627500 & 7 & 3389400 & 3 & $\mathbf{5 0 1 6 9 0 0}$ & 4 & 32,44 & 67,56 \\
2 & 453700 & 10 & 215500 & 15 & 669200 & 13 & 67,80 & 32,20 \\
3 & 1134100 & 8 & 480500 & 11 & 1614600 & 11 & 70,24 & 29,76 \\
4 & 2701200 & 4 & 3869500 & 1 & $\mathbf{6 5 7 0 7 0 0}$ & 2 & 41,11 & 58,89 \\
5 & 3172400 & 3 & 1621200 & 8 & $\mathbf{4 7 9 3 6 0 0}$ & 5 & 66,18 & 33,82 \\
6 & 452400 & 11 & 1062900 & 10 & 1515300 & 12 & 29,86 & 70,14 \\
7 & 304700 & 13 & 3692200 & 2 & $\mathbf{3 9 9 6 9 0 0}$ & 7 & 07,62 & 92,38 \\
8 & 388800 & 12 & 192000 & 16 & 580800 & 14 & 66,94 & 33,06 \\
9 & 4205300 & 2 & 1104600 & 9 & $\mathbf{5 3 0 9 9 0 0}$ & 3 & 79,20 & 20,80 \\
10 & 131900 & 16 & 17700 & 17 & 149600 & 17 & 88,17 & 11,83 \\
11 & 181400 & 14 & 258700 & 14 & 440100 & 15 & 41,22 & 58,78 \\
12 & 28200 & 17 & 345900 & 12 & 374100 & 16 & 07,54 & 92,46 \\
13 & 2364700 & 5 & 314500 & 13 & 2679200 & 9 & 88,26 & 11,74 \\
14 & 1855800 & 6 & 2158000 & 6 & $\mathbf{4 0 1 3 8 0 0}$ & 6 & 46,24 & 53,76 \\
15 & 1073200 & 9 & 2141000 & 7 & $\mathbf{3 2 1 4 2 0 0}$ & 8 & 33,39 & 66,61 \\
16 & 150200 & 15 & 2421700 & 5 & 2571900 & 10 & 05,84 & 94,16 \\
17 & 6068400 & 1 & 3022000 & 4 & $\mathbf{9 0 9 0 4 0 0}$ & 1 & 66,76 & 33,24 \\
\hline Média & $\mathbf{1 5 4 6 7 0 0}$ & & $\mathbf{1 5 4 7 4 8 8}$ & & $\mathbf{3 0 9 4 1 8 8}$ & & & \\
\hline
\end{tabular}

Fonte: Resultados da pesquisa.

Torna-se evidente, nesta análise, que o setor de carne suína também possui grande importância, quanto ao impacto para trás. Pelo índice de Rasmussen-Hirschman para trás, nos anos de 1980 e 1995, percebe-se que esse setor apresentou valores maiores que a unidade; quanto ao GHS, o seu PBL foi de $96,14 \%$, em 1980 , e de $88,17 \%$, em 1995, resultados que retratam, portanto, a importância desse impacto.

\section{Conclusões}

Os setores de produção (setor 2. Suínos) e abate e processamento (setor 10. Carne suína) da cadeia suinícola de Minas Gerais foram considerados setores-chave apenas segundo os índices de Rasmussen-Hirschman e do campo de influência. Assim, fatores que provoquem alterações nas demandas finais destes setores deverão resultar em impactos significativos na economia mineira. 
Pelo índice Rasmussen-Hirschman, nos dois períodos de análise, verificou-se que variações na produção do setor 2 poderiam estimular grande número de setores da economia mineira, pois apresentou grande impacto para frente e para trás. Já no setor 10, constatou-se que estímulos decorrentes de um impacto na sua produção deveriam se concentrar em poucos setores da economia, pois este é um setor que, dentre todos os outros, é o mais relacionado com a demanda final.

O índice do campo de influência do setor 2 indicou que este apresentou capacidade de influenciar para frente (coeficientes de venda) e para trás (coeficientes de compra), nos anos de 1980 e 1995; e os coeficientes de venda foram sensivelmente ampliados no último ano. O setor 10, por outro lado, só apresentou capacidade de influenciar para trás (obteve apenas coeficientes de compra), acentuada em 1995.

Apesar de os setores 2 e 10 não terem sido considerados setores-chave pelo índice puro de ligação (GHS), nesta análise, constatou-se que são muito importantes, como demandantes de insumos, para os demais setores da economia mineira.

Em face dessas conclusões e dado que esses setores continuaram aumentando a sua participação na economia de Minas Gerais nos anos subseqüentes a 1995, tem-se indicação de que eles devam ter prioridade na alocação de recursos e na estratégia de promoções industriais por meio de políticas estaduais.

\section{Referências bibliográficas}

BLISKA, F. M. de M., GUILHOTO, J. J. M., Importância dos setores de produção e de abate e processamento animal para a economia brasileira. Revista de Economia e Sociologia Rural, v. 39, n.1, p.9-34, 2001.

BLISKA, F. M. de M., GUILHOTO, J. J. M., IGREJA, A. C. M. Participação da agropecuária e da indústria de carnes na economia brasileira: um modelo inter-regional de insumo-produto. In: SOBER 2001. CD-ROM.

CAVALCANTI, J. E. A. Relações estruturais na economia brasileira: o caso do Nordeste. Revista Econômica do Nordeste, Fortaleza, v.22, n. 1-4, jan/dez 1991. 
Importância e encadeamento dos setores de produção e abate e processamento da cadeia suinícola em Minas Gerais

COSTA, T. V. M., OLTRAMARI, A. P., MONTOYA, M. A., ONGARATTO, A. P., BENETTI, L. A Competitividade da Suinocultura da Região da Produção/Rs Através da Análise do Cluster Agroindustrial. In: SOBER, 2002. CD-ROM

DIAWARA, M. Dimensionamento do agronegócio no Estado de Minas Gerais. Viçosa: Universidade Federal de Viçosa 2002. 94 p. Tese (Mestrado em Economia Aplicada) - Universidade Federal de Viçosa 2002.

DUARTE FILHO, F. C. D., CHIARI, J. R. P. Características estruturais da economia mineira: uma análise inter-regional de insumo-produto. Cadernos BDMG, Belo Horizonte, n.4, p.11-43, JAN. 2002.

FERNANDES, C. L. L, A inserção de Minas Gerais na economia nacional: uma análise insumo-produto inter-regional. Nova Economia, Belo Horizonte, número especial, 1997, p.85-178.

FUNDAÇÃO JOÃO PINHEIRO, CEI - Centro de Estatísticas e Informações. Disponível em: < http://www.fjp.com.br > . Acesso em: JUN. 2002.

FURTUOSO, M. C. O., GUILHOTO, J. J. M. Estimativa e mensuração do produto interno bruto do agronegócio da economia brasileira, 1994 a 2000. Revista de Economia e Sociologia Rural, v. 41, n.4, p.803-827, 2003.

GOMES, M. F. M., As cadeias agroindustriais de carne. In: Minas Gerais do Século XXI. Banco de Desenvolvimento de Minas Gerais (BDMG). Belo Horizonte: Rona Editora, volume IV, Transformando o desenvolvimento na agropecuária. p.59 a 86. 2002.

GUILHOTO, J. J. M, SONIS, M., HEWEINGS, G. J. D. Linkages and multipliers in a multiregional framework: integration of alternative approaches. Illinois: University of Illinois, Regional Economics Applications Laboratory, 1996. 20p.

INSTITUTO BRASILEIRO DE GEOGRAFIA E ESTATÍSITCA. Censo Agropecuário (Minas Gerais) 1980. Rio de Janeiro: IBGE, 1980.

de Janeiro: IBGE, 1996.

. Censo Agropecuário (Minas Gerais) 1995/1996. Rio

MONTOYA, M. A., GUILHOTO, J. J. M. O agronegócio brasileiro entre 1959 e 1995: dimensão econômica, mudança estrutural e tendências. In: 
$\mathrm{O}$ agronegócio brasileiro no final do século XX: estrutura produtiva, arquitetura organizacional e tendências. Passo Fundo (RS), UPF editora, 2000, cap 1, p.3-32, v.1.

PORDEUS, I. A., LOBATO, P. L. Uma visão do novo desenvolvimento. In: Minas Gerais do Século XXI. Banco de Desenvolvimento de Minas Gerais (BDMG). Belo Horizonte: Rona Editora, volume especial, 84p. 2002.

SANTANA, A. C. A dinâmica do complexo agroindustrial e o crescimento econômico no Brasil. Viçosa: Universidade Federal de Viçosa, 1994. 302 p. Tese (Doutorado em Economia Rural) - Universidade Federal de Viçosa ,1994.

SANTANA, J. R., SOARES, F. A., Critérios para uma política industrial regional: uma aplicação ao caso do nordeste. Estudos Econômicos n.022, Junho de 2000. Centro de Estudo de Economia Regional - CAEN, Fortaleza, Universidade Federal do Ceará. Capturado em 2002. http:// www.caen.ufc.br.

SILVEIRA, S. F. R. Inter-relações econômicas dos estados na bacia do rio São Francisco: uma análise de insumo-produto. Piracicaba: Escola Superior de Agricultura "Luiz de Queiroz" 2000. 245p Tese (Doutorado em Economia Aplicada) - Universidade de São Paulo 2000.

SONIS, M., HEWINGS, G. J. D. Error and sensitivy input-output analisys: a new aproach. In Miller, R. E., POLENSKE, K. R., ROSE, A. Z. (eds) . Frontiers of input-output analysis. New York, Oxford University Press, 1989.

SONIS, M., HEWINGS, G. J. D. Fields of influence in input-output systems. Urbana, University of Illinois, Regional Economics Applications Laboratory, 1994.

SUINOCULTURA INDUSTRIAL, Anuário 2003. Análise do mercado suinícola, n.01'2003, ano 25, edição 166, p.14-19.

TOSTA, M.C.R Potencialidades e encadeamentos da cadeia suinícola em Minas Gerais. Viçosa: UFV, 2003. 102p. Tese (Mestrado em Economia Aplicada) - Universidade Federal de Viçosa, 2003.

Recebido em março de 2004 e revisto em março de 2005. 